OPEN ACCESS

Edited by:

Claude E. Guérin

Hospices Civils de Lyon, France

Reviewed by:

Laura Borgstedt,

Technical University of

Munich, Germany

Ildiko Toth

University of Pécs, Hungary

*Correspondence:

Sébastien Gibot

s.gibot@chru-nancy.fr

Specialty section: This article was submitted to Intensive Care Medicine and Anesthesiology,

a section of the journal

Frontiers in Medicine

Received: 05 June 2021 Accepted: 25 November 2021 Published: 22 December 2021

Citation:

Gibot S, Conrad M, Courte G and

Cravoisy A (2021) Positive

End-Expiratory Pressure Setting in

COVID-19-Related Acute Respiratory

Distress Syndrome: Comparison

Between Electrical Impedance

Tomography, PEEP/FiO 2 Tables, and

Transpulmonary Pressure.

Front. Med. 8:720920

doi: 10.3389/fmed.2021.720920

\section{Positive End-Expiratory Pressure} Setting in COVID-19-Related Acute Respiratory Distress Syndrome: Comparison Between Electrical Impedance Tomography, $\mathrm{PEEP} / \mathrm{FiO}_{2}$ Tables, and Transpulmonary Pressure

\author{
Sébastien Gibot*, Marie Conrad, Guilhem Courte and Aurélie Cravoisy
}

Service de Réanimation Médicale, Hôpital Central, CHRU, Nancy, France

Introduction: The best way to titrate the positive end-expiratory pressure (PEEP) in patients suffering from acute respiratory distress syndrome is still matter of debate. Electrical impedance tomography (EIT) is a non-invasive technique that could guide PEEP setting based on an optimized ventilation homogeneity.

Methods: For this study, we enrolled the patients with 2019 coronavirus disease (COVID-19)-related acute respiratory distress syndrome (ARDS), who required mechanical ventilation and were admitted to the ICU in March 2021. Patients were monitored by an esophageal catheter and a 32-electrode EIT device. Within $48 \mathrm{~h}$ after the start of mechanical ventilation, different levels of PEEP were applied based upon $\mathrm{PEEP} / \mathrm{FiO}_{2}$ tables, positive end-expiratory transpulmonary $\left(\mathrm{P}_{\mathrm{L}}\right) / \mathrm{FiO} 2$ table, and EIT. Respiratory mechanics variables were recorded.

Results: Seventeen patients were enrolled. PEEP values derived from EIT (PEEPEIT) were different from those based upon other techniques and has poor in-between agreement. The PEEPEIT was associated with lower plateau pressure, mechanical power, transpulmonary pressures, and with a higher static compliance (Crs) and homogeneity of ventilation.

Conclusion: Personalized PEEP setting derived from EIT may help to achieve a more homogenous distribution of ventilation. Whether this approach may translate in outcome improvement remains to be investigated.

Keywords: ARDS, COVID-19, PEEP, electrical tomography impedance, mechanical ventilation

\section{INTRODUCTION}

Despite progresses in acute respiratory distress syndrome (ARDS) management, the best way to titrate a positive end-expiratory pressure (PEEP) is not straightforward (1). The "right" PEEP should allow for optimized lung recruitment while minimizing over-distention. To this aim, clinicians can use $\mathrm{PEEP}-\mathrm{FiO}_{2}$ tables (2), transpulmonary pressure $\left(\mathrm{P}_{\mathrm{L}}\right)(3)$, or electrical impedance tomography (EIT). 
The transpulmonary pressure is measured using an esophageal balloon catheter that approximates the pleural pressure. Using this technique, PEEP has to be set to maintain the end-expiratory $\mathrm{P}_{\mathrm{L}}$ above zero to avoid collapse of dependent dorsal lung regions, and the end-inspiratory $\mathrm{P}_{\mathrm{L}}$ below $20-25 \mathrm{cmH}_{2} \mathrm{O}$ to decrease the risk of overdistension of non-dependent regions.

Electrical impedance tomography (EIT) is a non-invasive technique giving dynamic information on regional ventilation that can be embarked in modern ventilators. Regional hypoventilated lung units ("Silent spaces") correspond to both collapsed areas in the dependent territories, and distended areas in the non-dependent regions. Using this technique, PEEP is set to minimize the percentage of total silent spaces.

We describe a case series of patients suffering from 2019 coronavirus disease (COVID-19)-related ARDS in whom we compared PEEP settings based on $\mathrm{PEEP} / \mathrm{FiO}_{2}$ tables, $\mathrm{P}_{\mathrm{L}} / \mathrm{FiO} 2$ table, and EIT.

\section{METHODS}

In March 2021, we enrolled some mechanically ventilated patients who were admitted to our Intensive Care Unit (ICU) because of a COVID-19-related moderate-to-severe ARDS. The diagnosis of COVID-19 relied upon positive result on polymerase chain reaction of sputum or nasal swab. The Ethic Committee of our University Hospital approved this study with a waiver of informed consent because of the use of routine procedures, as well as the use of de-identified data.

All patients were ventilated in volume control mode [tidal volume (Vt): $6-7 \mathrm{ml} / \mathrm{kg}$ ideal body weight (IBW)], with $\mathrm{FiO}_{2}$ set to achieve peripheral oxygen saturation $\left(\mathrm{SpO}_{2}\right)$ between 92 and $95 \%$, and respiratory rate (RR) set to reach $\mathrm{PaCO}_{2}$ between 38 and $45 \mathrm{mmHg}$. Transpulmonary pressures were measured with the use of an esophageal balloon catheter (Nutrivent; Sidam, Mirandola, Italy) after its correct positioning has been verified through passive chest compression during occlusion. As part of our routine monitoring, patients were also equipped with a 32-electrode soft-textile EIT belt (Sentec; Therwil, Switzerland), which was directly connected to the ventilator (ELISA 800 VIT, Lowenstein Medical; Kronberg, Germany). Some maneuvers were performed in supine position after $24-48 \mathrm{~h}$ of mechanical ventilation while the patients were still sedated (midazolam and sufentanyl) and paralyzed (cisatracurium or atracurium). Respiratory mechanics variables were recorded after $10 \mathrm{~min}$ at different PEEP levels while all the other parameters $\left(\mathrm{FiO}_{2}, \mathrm{Vt}, \mathrm{RR}\right.$, flow rates, etc.) remained unchanged.

Positive end-expiratory pressure (PEEP) was first set according to the lower, then, to the higher PEEP/FiO 2 ALVEOLI table (2). Next, PEEP as based upon end-expiratory $\mathrm{P}_{\mathrm{L}} / \mathrm{FiO}_{2}$ table, was applied (3). Finally, an automated decremental PEEP trial was performed under EIT monitoring (Best-PEEP-Tool, Lowenstein Medical): PEEP was set at $24 \mathrm{cmH}_{2} \mathrm{O}$ (corresponding to the maximum $\mathrm{PEEP}$ in the $\mathrm{PEEP} / \mathrm{FiO}_{2}$ table) and was reduced by $2 \mathrm{cmH}_{2} \mathrm{O}$ every 10 inspirations until $6 \mathrm{~cm} \mathrm{H}_{2} \mathrm{O}$, with a 3-s end-expiratory hold between decremental steps. For each PEEP values, percentages of relatively collapsed and overdistended lung regions were given by the EIT, and the "best" PEEP (PEEP was considered as the lowest level associated with the lowest total percentage of the lung silent spaces (collapsed + distended).

Data are presented as median (interquartile range) and are compared using Wilcoxon signed-rank test. Bias and limits of agreement between different approaches were calculated with the Bland-Altman approach. Statistical analyses were performed by GraphPad software (La Jolla, CA, USA) with two-tailed $p<0.05$ deemed as significant.

\section{RESULTS}

Seventeen patients ( 15 men, 2 women) were enrolled. Median age was 65 (62-71) years, and body mass index was 31.1 (28.5-33.0). The ARDS was severe in 6 and moderate in 11 patients, while the $\mathrm{PaO}_{2} / \mathrm{FiO}_{2}$ was 136 (103-155), Vt 6.6 (6.2-7.0) $\mathrm{mL} / \mathrm{kg}$ IBW, and RR 24 (22-27), respectively. Twelve patients were under high-flow oxygen therapy for a median of $1(1,2)$ day before intubation. All patients, except for one, were discharged alive.

Positive end-expiratory pressure derived from EIT (PEEP $\mathrm{EIT}_{\text {), }}$ corresponding to the lowest level of PEEP achieving the lowest percentage of total silent spaces (distended + collapsed), was significantly different from the other PEEP values. It was higher than the lower $\mathrm{PEEP} / \mathrm{FiO}_{2}$ table, and lower than the higher $\mathrm{PEEP} / \mathrm{FiO}_{2}$ or $\mathrm{P}_{\mathrm{L}} / \mathrm{FiO}_{2}$ tables (Table 1). The Bland-Altman analysis showed that $\mathrm{PEEP}_{\text {EIT }}$ was $1.3 \mathrm{~cm} \mathrm{H}_{2} \mathrm{O}$ higher than the lower $\mathrm{PEEP} / \mathrm{FiO}_{2}$ table with limits of agreement from -8.5 to $11.2 \mathrm{~cm} \mathrm{H} \mathrm{H}_{2} \mathrm{O}$. By contrast, PEEP $\mathrm{EIT}_{\mathrm{T}}$ was 5 and $4 \mathrm{~cm} \mathrm{H}_{2} \mathrm{O}$ lower, respectively, than higher $\mathrm{PEEP} / \mathrm{FiO}_{2}$ and $\mathrm{P}_{\mathrm{L}} / \mathrm{FiO}_{2}$ tables, with again wide limits of agreement (Figure 1).

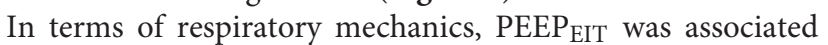
with lower plateau pressure, mechanical power, transpulmonary pressures, and with a higher static compliance (Crs) than higher $\mathrm{PEEP} / \mathrm{FiO}_{2}$ or $\mathrm{P}_{\mathrm{L}} / \mathrm{FiO}_{2}$ tables (Table 1). Driving pressures were not significantly different.

A better distribution of ventilation was achieved with PEEP $_{\text {EIT }}$ : lung collapse was lower with PEEP EIT $_{\text {than }}$ with lower $\mathrm{PEEP} / \mathrm{FiO}_{2}$ table ( 9 vs. $13 \% ; p=0.04$ ), while lung distension was reduced as compared to higher $\mathrm{PEEP} / \mathrm{FiO}_{2}$ and $\mathrm{P}_{\mathrm{L}} / \mathrm{FiO}_{2}$ tables $(6$ vs. 20 and 13\%, respectively; $p<0.01$ ) (Figure 1).

\section{DISCUSSION}

Personalized PEEP guided by EIT, with the aim to minimize relative alveolar distention and collapse, was different than PEEP based upon $\mathrm{PEEP} / \mathrm{FiO}_{2}$ or $\mathrm{P}_{\mathrm{L}} / \mathrm{FiO}_{2}$ tables. Although in terms of respiratory mechanics, PEEP ${ }_{\text {EIT }}$ did not differ from lower $\mathrm{PEEP} / \mathrm{FiO}_{2}$ table. There were very important individual variations as witnessed by the wide range of limit agreement in Bland-Altman analyses. Therefore, each patient exhibited different lung properties that cannot be ascertained by using global mechanics parameter such as driving or transpulmonary pressures, compliance, or pressure-volume curves. This may explain the negative results of important clinical trials, which compared low vs. high PEEP in ARDS patients $(2,4)$. 
TABLE 1 | Effect of positive end-expiratory pressure (PEEP) settings on respiratory mechanics.

\begin{tabular}{|c|c|c|c|c|}
\hline Variable & Lower $\mathrm{PaO}_{2} / \mathrm{FiO}_{2}$ table & Higher $\mathrm{PaO}_{2} / \mathrm{FiO}_{2}$ table & $\mathrm{P}_{\mathrm{L}} / \mathrm{FiO}_{2}$ table & PEEP \\
\hline PEEP $\left(\mathrm{cm} \mathrm{H}_{2} \mathrm{O}\right)$ & 10 (10 to 14$)$ & 17 (16 to 20$)$ & 15 (14 to 20$)$ & $13(12 \text { to } 14)^{\star \#}$ \\
\hline P PLAT $\left(\mathrm{cm} \mathrm{H} \mathrm{H}_{2} \mathrm{O}\right)$ & 23 (20 to 26$)$ & 33 (28 to 38$)$ & 29 (24 to 37$)$ & $25(22 \text { to } 27)^{\#}$ \\
\hline Driving Pressure $\left(\mathrm{cm} \mathrm{H}_{2} \mathrm{O}\right)$ & 12 (10 to 14$)$ & $14(12$ to 18$)$ & 13 (11 to 16$)$ & $12(11$ to 13$)$ \\
\hline $\mathrm{C}_{\mathrm{RS}}\left(\mathrm{mL} / \mathrm{cm} \mathrm{H} \mathrm{H}_{2} \mathrm{O}\right)$ & 39 (34 to 48) & 30 (24 to 37$)$ & 35 (26 to 43 ) & 38 (34 to 45$)^{\#}$ \\
\hline Mechanical Power (J/min) & 25.1 (22.7 to 34.3$)$ & 34.4 (28.0 to 43.6$)$ & 34.1 (26.0 to 40.7$)$ & $28.4(24.4 \text { to } 32.0)^{\#}$ \\
\hline Inspiratory Transpulmonary pressure $\left(\mathrm{cm} \mathrm{H}_{2} \mathrm{O}\right)$ & 6.6 (4.3 to 13.5$)$ & 17.5 (9.9 to 21.6$)$ & 14.7 (9.4 to 18.7$)$ & $11.5(6.4 \text { to } 14.3)^{\#}$ \\
\hline Expiratory Transpulmonary pressure $\left(\mathrm{cm} \mathrm{H}_{2} \mathrm{O}\right)$ & $-0.3(-2.8$ to 3.6$)$ & 5.0 (2.0 to 8.0$)$ & $4.0(1.5$ to 6.5$)$ & $1.3(0.1 \text { to } 2.0)^{\#}$ \\
\hline Silent spaces (\%) & 18 (10 to 26$)$ & 30 (13 to 48$)$ & 23 (17 to 35$)$ & $16(9 \text { to } 23)^{\#}$ \\
\hline
\end{tabular}

* $p<0.05$ PEEPEIT vs. Lower $\mathrm{PaO}_{2} / \mathrm{FiO}_{2}$ table.

$\# p<0.05$ PEEPEIT vs. Higher $\mathrm{PaO}_{2} / \mathrm{FiO}_{2}$ and $\mathrm{P}_{\mathrm{L}} / \mathrm{FiO}_{2}$ tables.

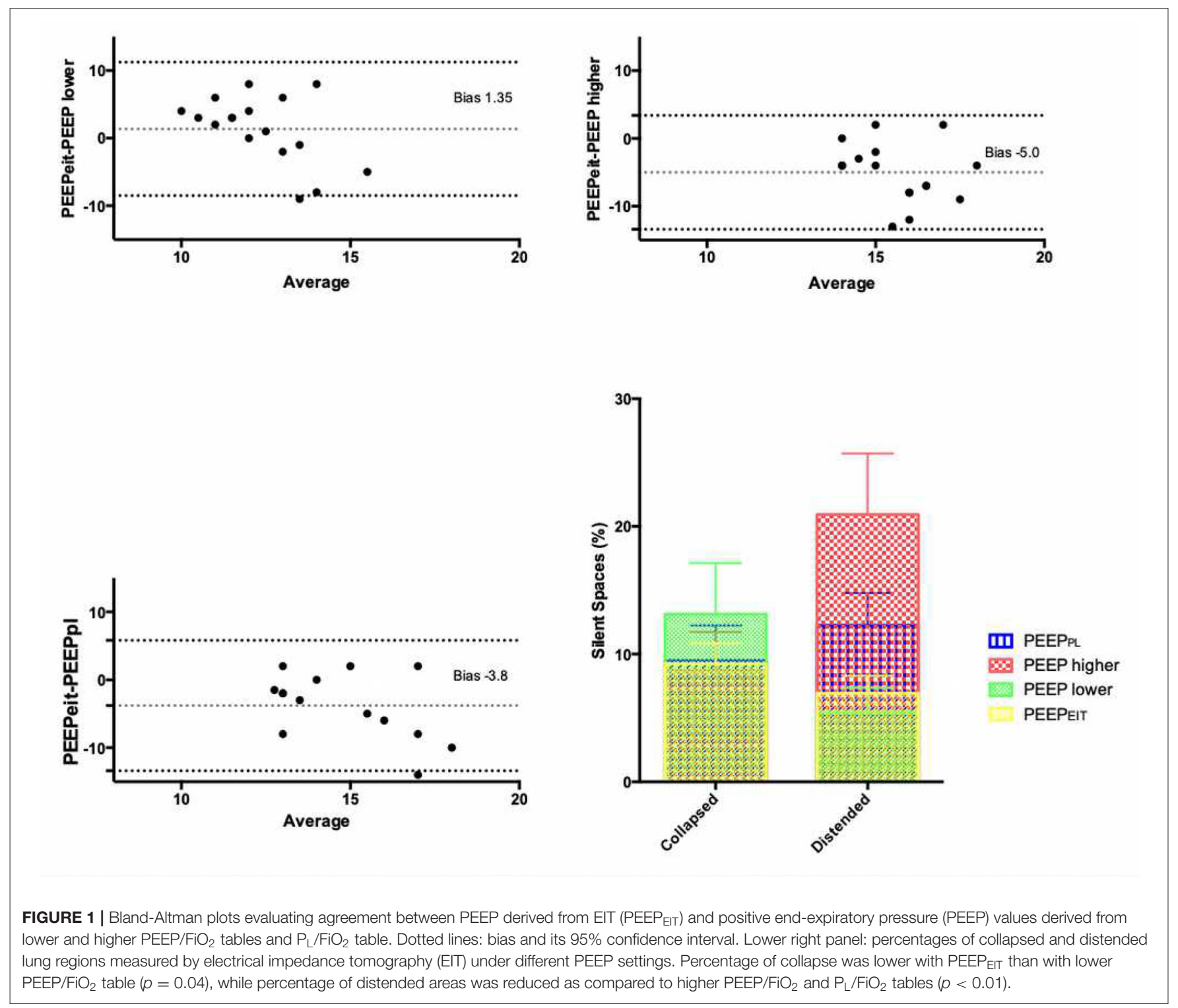

Several other recent studies evaluated EIT-guided PEEP titration. Van der Zee et al. (5) and Sella et al. (6) have

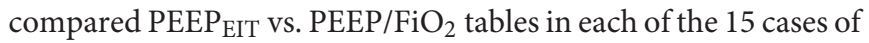

COVID-19-related ARDS patients. In both studies, PEEP values differed with important individual variations. Interestingly, PEEPEIT was lower $\left(12 \mathrm{cmH}_{2} \mathrm{O}\right)$ in the Sella study than in the 
Van der Zee's $\left(21 \mathrm{~cm} \mathrm{H} \mathrm{H}_{2} \mathrm{O}\right)$. This highlights the huge variability between patients with ARDS, depending on weight, age, sex, or duration of mechanical ventilation.

When comparing PEEP $\mathrm{EIT}_{\text {and }} \mathrm{P}_{\mathrm{L}} / \mathrm{FiO}_{2}$ table, Scaramuzzo et al. (7), in 20 patients under non-COVID-19 ARDS, found no correlation between the values given by the 2 techniques. As in

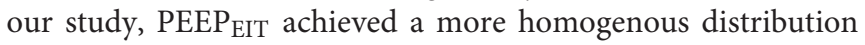
of ventilation.

Our work has several limitations. First, we only included patients with COVID-19. Whether these patients behaved similarly to those suffering from non-COVID-19 ARDS in terms of respiratory mechanics is still matter of debate. Second, most of our patients were over-weighted. Hence, this may have contributed to the low agreement between techniques. Finally, only 17 patients have been enrolled, precluding any generalization. However, each patient was its own control, and we just wanted to underline the poor agreement between routinely used techniques at the patient level.

The use of EIT allows for a personalized PEEP titration with the aim to minimize the total amount of pulmonary silent spaces.

\section{REFERENCES}

1. Sahetya SK, Golagher EC, Brower RG. Fifty years of research inn ARDS. Setting positive end-expiratory pressure in acute respiratory distress syndrome. Am J Respir Crit Care Med. (2017) 195:1429-38. doi: 10.1164/rccm.201610-2035CI

2. The National Heart, Lung, and Blood Institute ARDS Clinical Trials Network. Higher versus lower positive end-expiratory pressures in patients with the acute respiratory distress syndrome. $N$ Engl J Med. (2004). 351:32736. doi: 10.1056/NEJMoa032193

3. Beitler JR, Sarge T, Banner-Goodspeed VM, Gong MN, Cook D, Novack V, et al. EPVent-2 study group: effect of titrating positive end-expiratory pressure (PEEP) with an esophageal pressure-guided strategy vs an empirical high PEEP$\mathrm{FiO}_{2}$ strategy on death and days free from mechanical ventilation among patients with acute respiratory distress syndrome: a randomized clinical trial. JAMA. (2019) 321:846-57. doi: 10.1001/jama.2019.0555

4. Mercat A, Richard JC, Vielle B, Jaber S, Osman D, Diehl JL, et al. End-expiratory pressure (Express) study group. Positive end-expiratory pressure setting in adults with acute lung injury and acute respiratory distress syndrome: a randomized controlled trial. JAMA. (2008) 299:64655. doi: 10.1001/jama.299.6.646

5. van der Zee P, Somhorst P, Endemann H, Gommers D. Electrical impedance tomography for positive end-expiratory pressure titration in COVID-19 related ARDS. Am J Respir Crit Care Med. (2020) 202:2804. doi: 10.1164/rccm.202003-0816LE

6. Sella N, Zarantonello F, Andreatta G, Gagliardi V, Boscolo A, Navalesi P. Positive end-expiratory pressure titration in COVID-19 acute respiratory
Whether this approach could translate in outcome improvement remains to be investigated.

\section{DATA AVAILABILITY STATEMENT}

The raw data supporting the conclusions of this article will be made available by the authors, without undue reservation.

\section{ETHICS STATEMENT}

The studies involving human participants were reviewed and approved by Comité d'éthique du CHRU de Nancy. Written informed consent for participation was not required for this study in accordance with the national legislation and the institutional requirements.

\section{AUTHOR CONTRIBUTIONS}

SG designed the study, collected and analyzed data, and wrote the manuscript. MC, GC, and AC collected and analyzed data. All authors read and approved the manuscript.

failure: electrical impedance tomography vs. $\mathrm{PEEP} / \mathrm{FiO}_{2}$ tables. Crit Care. (2020) 24:540. doi: 10.1186/s13054-020-03242-5

7. Scaramuzzo G, Spadaro S, Dalla Corte F, Waldmann AD, Böhm SH, Ragazzi $\mathrm{R}$, et al. Personalized positive end-expiratory pressure in acute respiratory distress syndrome: Comparison between optimal distribution of regional ventilation and positive transpulmonary pressure. Crit Care Med. (2020) 48:1148-56. doi: 10.1097/CCM.0000000000004439

Conflict of Interest: The authors declare that the research was conducted in the absence of any commercial or financial relationships that could be construed as a potential conflict of interest.

Publisher's Note: All claims expressed in this article are solely those of the authors and do not necessarily represent those of their affiliated organizations, or those of the publisher, the editors and the reviewers. Any product that may be evaluated in this article, or claim that may be made by its manufacturer, is not guaranteed or endorsed by the publisher.

Copyright (C) 2021 Gibot, Conrad, Courte and Cravoisy. This is an open-access article distributed under the terms of the Creative Commons Attribution License (CC BY). The use, distribution or reproduction in other forums is permitted, provided the original author(s) and the copyright owner(s) are credited and that the original publication in this journal is cited, in accordance with accepted academic practice. No use, distribution or reproduction is permitted which does not comply with these terms. 